\title{
AOR
}

Selected Papers of \#AolR2021:

The 22nd Annual Conference of the Association of Internet Researchers Virtual Event / 13-16 Oct 2021

\section{REMOTE WORK BETWEEN NARRATIVES OF INDIPENDENCE AND FRACTURED EXPERIENCES. A QUALITATIVE RESEARCH DURING THE PANDEMIC CRISIS.}

\author{
Elisabetta Risi \\ IULM University of Milan \\ Riccardo Pronzato \\ IULM University of Milan
}

\section{Introduction}

Since the introduction of social distancing measures in several countries, it emerged even more clearly than before a division of labour between individuals that can work in a 'footloose' manner, and 'fixed' workers, i.e. place-based jobs which imply 'the need for physical proximity to a particular spot' (Huws, 2006, p. 49). During the lockdown, the latter category was further divided by governments in essential and locked workers.

Specifically, the coronavirus crisis showed the possibility and importance of working from home for many employers and employees, especially in the West (Berg et al., 2020). Remote working through digital technologies has become an emerging trend in recent years (Eddleston and Mulki, 2017), hence, for some people, such as knowledge workers, working remotely was not a new experience. However, most of the white-collar workers were used to work remotely only occasionally and often unofficially.

This paper is based on a qualitative research aims to study how remote workers experienced their job and everyday life during the Italian lockdown (9 March - 3 May 2020), imposed by the national government to contain the spread of COVID-19. Specifically, this contribution focuses on the interdependence of work and everyday life, and the role of digital devices and online platforms during the home-confinement period, and it explores the consequences of social distancing measures on remote workers and on their working and personal conditions. 


\section{Framework}

Digital platforms are structurally transforming work and their social representations, by facilitating increasingly connected societies, in which production, consumption and services are available 24/7. Today spaces and times of work increasing interweave with other areas of life, by becoming interdependent on each other, within a state of permanent connectivity.

Connectivity structures the digital society ambivalently: on the one hand, dominant narratives present connectivity as a liberating power, enhanced by the dimensions of immediacy and speed, which allow to increasingly access "knowledge", while giving people more independence and the possibility of building relationships and contacts beyond the traditional constraints of time and space. On the other hand, it is precisely ubiquitous connectivity, i.e., the possibility of "always being there", that favour the blurring between personal and work boundaries, and the following impossibility to distinguish between home and working spaces, or familiar and professional relationships (Risi, 2015).

The subjectivity of workers is ambivalent as well. For example, workers are legally considered by companies as freelancers, within a discursive regime based on narratives of flexibility and self-determination, while they are, in fact, subjected to new form of managerial governmentality (Banks, 2007) of surveillance and control more pervasive than the ones of subordinate labour in the past. Furthermore, their performances are segmented, individualised, and physically separated from the ones of other workers. Within this scenario, it emerges a neoliberal subjectivity defined by individual autonomy and proactive attitudes towards work and social life (Armano et al, 2020).

\section{Method}

The study draws from 20 in-depth semi-structured interviews with Italian remote workers, i.e., individuals which could work from home through digital technologies during the national lockdown. The research design adopted a criterion sample, thereby selecting participants according to specific variables: gender and age. Indeed, the sample is gender balanced ( 10 males and 10 females) and it includes two age subgroups (10 participants aged 30-45 and 10 aged 46-60). All the interviewees were interviewed during the Italian lockdown (March-April 2020). The participants were all recruited in the North of Italy - where there are the most populous and digitized regions in this country, as well as the ones in which COVID-19 spread earlier.

\section{Main results}

Results highlight that during the lockdown, some participants attempted to cope with the unprecedented triumph of technologically mediated work, others described remote work as liberating and attractive, as it avoids commuting and allow people to organize their activities autonomously, without constraints of space and time. However, their initial enthusiasm decreased after a few weeks of domestic confinement. 
The convergence of different spaces and times into the home favoured the erosion of the distinction between private and professional life, which become both saturated by digital media. Individuals tried to reterritorialize both personal and working interactions in mediated relational spaces, but results support that workers felt the lack of some relational aspects of the workplace and that a 'work-to-family conflict' often emerged (Eddleston \& Mulki, 2017).

Then, the burden of this fractured experience appeared as dramatically heavier for women with young children. In several interviews, participants highlight that workers have little organizational autonomy. Companies decide how long and when they have to work, while the projects that had to be submitted often overlap with the need to follow children in their digital distance learning experiences. The experiences reported, especially by women, are those of working and educational deadlines that coincide at the same time, within a unique domestic context, and through protocols established by digital platforms.

Working from implied, thus, a state of always-on life in which social relationships and the workflow were re-constructed and inevitably shaped by online platforms. If digital technologies have been often promoted as devices that can free us from material constrains, allowing us to work in the place we prefer, whenever we want, this shift have been already proved to have important consequences, such as exacerbating a certain compulsion to work and encourage the tendency to consider work as the focus of daily experiences and, more broadly, of human life (Gregg, 2011).

Thus, the experience of remote workers that emerges is a "fractured" one (Huws, 2006), which appears as a characteristic feature of forced and continuous remote work. Individuals have to cope with the consequences of an 'always on' life, in which digital and social inequalities appear exacerbated by the pandemic. In this scenario, platforms emerged as a ubiquitous presence of 'logged labour' (Huws, 2016) and of all the realms of everyday life, which becomes to a greater extent a 'digital life' (Markham, 2020). Indeed, the coronavirus crisis has accentuated the infrastructural role of digital platforms (van Dijck et al, 2018) and intensified the 'deep mediatization' of social life (Couldry and Hepp, 2017) and labour, thereby normalizing transmedia work and the 'extension of already media saturated working conditions' (Fast and Jansson, 2019, p. 2).

\section{References}

Armano, E., Mazali, T., \& Teli, M. (2020). The production of neoliberal subjectivity in platform capitalism. Comparative interpretative hypotheses. Sociologia della comunicazione, 59, 106-126

Banks, M. (2007) The politics of cultural work, Basingstoke, UK, Palgrave Macmillan

Berg, J., Bonnet, F. \& Soares, F. (2020, May 11). Working from Home: Estimating theWorldwide Potential. Vox Column. Accessed April 13, 2021. Retrieved from: https://voxeu.org/article/working-home-estimating-worldwide-potential 
Couldry, N., \& Hepp, A. (2017). The mediated construction of reality. Cambridge, UK: Polity Press.

Eddleston, K. A., \& Mulki, J. (2017). Toward understanding remote workers' management of work-family boundaries: The complexity of workplace embeddedness. Group \& Organization Management, 42(3), 346-387. $\underline{10.1177 / 1059601115619548}$

Fast, K., \& Jansson, A. (2019). Transmedia work: Privilege and precariousness in digital modernity. New York: Routledge.

Gregg, M. (2011). Work's Intimacy. Cambridge, UK: Polity.

Huws, U. (2006). Fixed, Footloose, or Fractured: Work, Identity, and the Spatial Division of Labor in the Twenty-First Century City. Monthly Review, 57(10), 34-44.

Huws, U. (2016). Logged labour: a new paradigm of work organisation?. Work Organisation, Labour \& Globalisation, 10(1), 7-26

Risi E. (2015), "Intersezioni e confini del lavoro, tra spazi e tempi urbani e digitali. II caso dei knowledge workers a Milano", In Armano E., A. Murgia (eds.) Le reti del lavoro gratuito. Spazi urbani e nuove soggettività, Verona: Ombre Corte, pp. 5976.

Van Dijck, J., Poell, T., \& De Waal, M. (2018). The platform society: Public values in a connective world. Oxford, UK: Oxford University Press. 